\title{
Rainfall simulation to identify the storm-scale mechanisms of gully bank retreat
}

\author{
Vincent Chaplot ${ }^{\mathrm{a}, *}$, Jacqueline Brown ${ }^{\mathrm{b}}$, Phesheya Dlamini ${ }^{\mathrm{a}}$, Tarryn Eustice ${ }^{\mathrm{c}}$, Jean-Louis Janeau ${ }^{\mathrm{a}}$, \\ Graham Jewitt $^{\mathrm{d}}$, Simon Lorentz ${ }^{\mathrm{d}}$, Lauren Martin ${ }^{\mathrm{c}}$, Charmaine Nontokozo-Mchunu ${ }^{\mathrm{e}}$, Ernest Oakes ${ }^{\mathrm{d}}$, \\ Pascal Podwojewski ${ }^{a}$, Sylvain Revil ${ }^{\mathrm{d}}$, Cornelia Rumpel ${ }^{\mathrm{f}}$, Nhlakanipho Zondi ${ }^{\mathrm{d}}$ \\ a IRD - BIOEMCO c/o School of Bioresources Engineering and Environmental Hydrology, Rabie Saunders Building, \\ University of Kwazulu-Natal, Private Bag X01, Scottsville 3209, South Africa \\ ${ }^{\mathrm{b}}$ University of Pretoria, Pretoria 0002, South Africa \\ c The South African Sugarcane Research Institute (SASRI), P/Bag X 02, Mount Edgecombe, 4300 Durban, South Africa \\ d School of Bioresources Engineering and Environmental Hydrology, Rabie Saunders Building, University of Kwazulu-Natal, Private Bag X01, Scottsville 3209, South Africa \\ e Republic of South Africa Cedara Agricultural Research Institute, Private Bag X9059, Pietermaritzburg 3200, South Africa \\ ${ }^{\mathrm{f}}$ CNRS, Laboratoire de Biogéochimie des Milieux Continentaux (BIOEMCO), Centre INRA Versailles-Grignon, Bâtiment EGER, 78850 Thiverval-Grignon, France
}

\section{A R T I C L E I N F O}

\section{Article history:}

Available online $\mathrm{xxx}$

\section{Keywords:}

Gully erosion

Bank retreat

Involved mechanisms

South Africa

\begin{abstract}
A B S T R A C T
Gully erosion is one of the main causes of soil loss in drylands. Understanding the dominant mechanisms of erosion is important to achieve effective erosion control, thus in this study our main objective was to quantify the mechanisms involved in gully bank retreat as a result of three processes, falling of entire soil aggregates, transport of soil material by splash and by water running along gully banks (runoff), during rainfall events. The study was conducted in the sloping lands of the KwaZulu-Natal province, a region that is highly affected by gully erosion. Artificial rain was applied at $60 \mathrm{~mm} \mathrm{~h}^{-1}$ for $45 \mathrm{~min}$ at the vertical wall of a gully bank typical to the area. The splash material was collected by using a network of $0.045 \mathrm{~m}^{2}$ buckets. The sediments in the running water were assessed by sampling the runoff collected from a microplot inserted within the base of the bank, and collecting the fallen aggregates after the rainfall simulation was complete. Results indicated that the overall erosion for the simulation was $721 \mathrm{~g} \mathrm{~m}^{-2} \mathrm{~h}^{-1}$. Runoff erosion proved to be the dominant mechanism and amounted to $450 \mathrm{~g} \mathrm{~m}^{-2} \mathrm{~h}^{-1}$, followed by splash and fall down of aggregates (about $170 \mathrm{~g} \mathrm{~m}^{-2} \mathrm{~h}^{-1}$ ). Gully bank retreat occurred at a rate of $0.55 \mathrm{~mm} \mathrm{~h}^{-1}$ and assuming that the soil bulk density is $1.3 \mathrm{~g} \mathrm{~cm}^{-3}$, this corresponds to a retreat of $8.8 \mathrm{~mm} \mathrm{y}^{-1}$. Extrapolations to the watershed level, where about $500 \mathrm{~m}^{2}$ of gully bank are observed per hectare, would lead to an erosion rate of $4.8 \mathrm{tha}^{-1} \mathrm{y}^{-1}$. These limited results based on a simulated storm show that the three main mechanisms (runoff, splash and fall down of aggregates) are responsible for the retreat of gully banks and that to mitigate gully erosion, appropriate measures are required to control all three mechanisms. Further research studies are needed to confirm and to scale up, both in time and space, as these data are obtained at one location and from a single artificial storm.
\end{abstract}

(C) 2010 Elsevier B.V. All rights reserved.

\section{Introduction}

The issue of soil erosion is fast becoming a severe challenge to food supply, food security, human health, natural ecosystems as well as to the economic development of countries. Erosion leads to irreversible damage of cropping systems by removing fertile horizons of soils and reducing the water holding capacity and all the associated ecological functions (Lal, 1998). Linear erosion, which is defined as erosion due to the concentrated and channelized runoff and includes gully and ephemeral gully erosion, is also responsible for off-site consequences such as debris flow

\footnotetext{
* Corresponding author. Fax: +273326058 18

E-mail address: Vincent.Chaplot@ird.fr (V. Chaplot).
}

or the silting up of valley bottoms and reservoirs (Poesen et al., 1996).

In inter-tropical and tropical areas, linear erosion is considered to be one the main contributors to soil degradation and the sediment loads from river basins (IGBP, 1995). The literature shows that gullies account for most soil erosion (e.g., Poesen et al., 2002). For instance, in the tropical regions of southern China, linear erosion contributed up to $85 \%$ of sediment load from a $0.73 \mathrm{~km}^{2}$ catchment (DiCenzo and Luk, 1997).

On- and off-site effects of linear erosion may jeopardize the future of natural ecosystems and the economic development of societies. Consequently, better understanding of the mechanisms of linear erosion has become an important issue, because understanding linear erosion mechanisms and their controlling factors is fundamental to the identification of pos- 


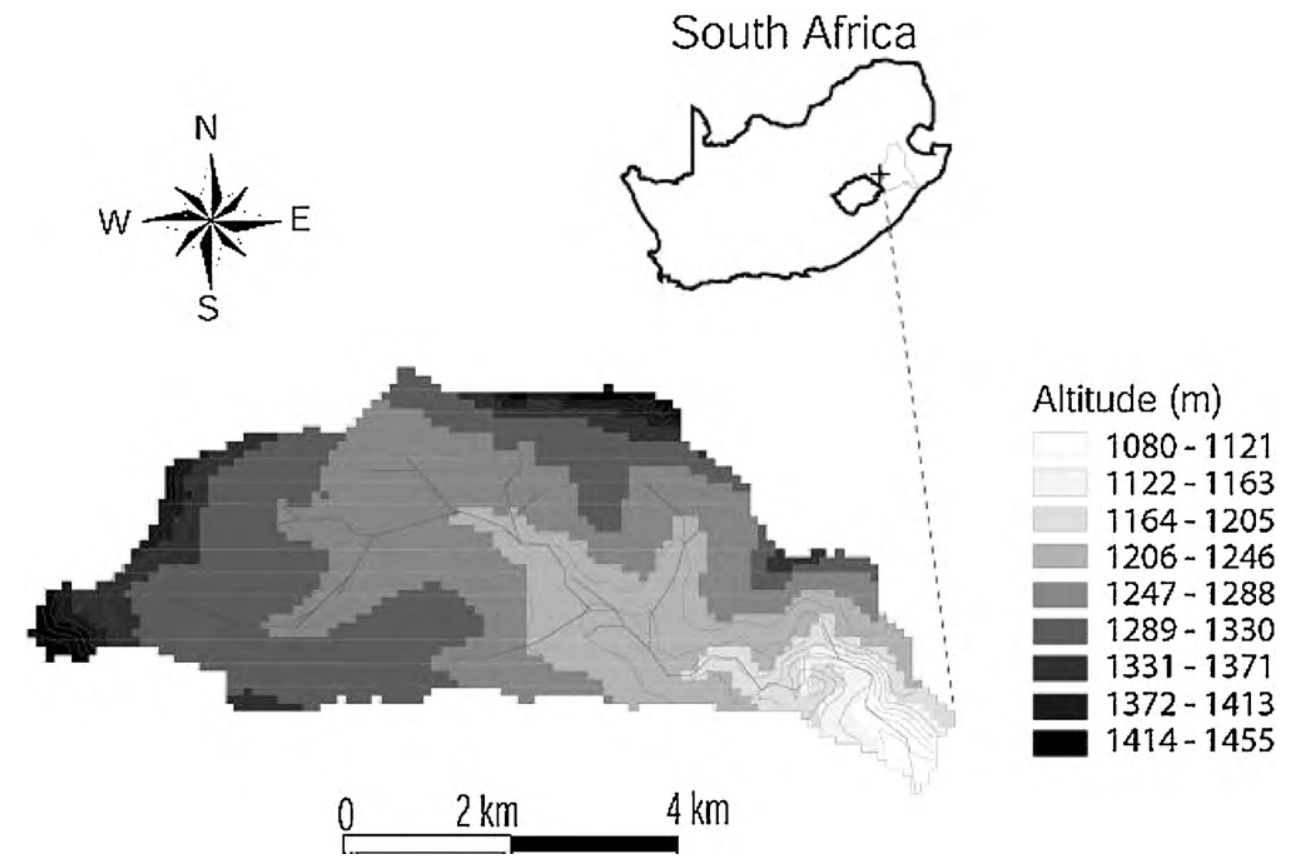

Fig. 1. Location of the study area in South Africa.

sible solutions to environmental issues associated with linear erosion.

Attempts at evaluating linear erosion mechanisms have been made over several years (Moore et al., 1994; Montgomery and Dietrich, 1994; Poesen et al., 1996; Nachtergaele et al., 2001) and mechanisms such as erosion due to concentrated surface flow or piping have been identified so far. However, once formed, erosion resulting from the lateral retreat of gully banks has shown to be the main source of the sediment exported from river basins and a main factor of control of gully evolution in landscapes (Vandekerckhove et al., 2001; Hu et al., 2007). Estimations made by Vandekerckhove et al. (2001) at 46 active bank gullies, of the Guadalentin and the Guadix basin in south east Spain, showed that the linear headcut retreat contributed to less than $10 \%$ of the total gully erosion. Most of the gully erosion thus occurs along the gully, via the lateral retreat of gully banks.

Despite such significant evidence, the mechanisms involved in the lateral retreat of gully banks are not quantified. Vandekerckhove et al. (2001) found that runoff has a positive correlation to linear headcut retreat, and therefore no impact on the lateral retreat of gully banks. Mechanisms, other than those linked to runoff, may control such a retreat, however little is known about them (Poesen et al., 2002). In order to mitigate gully bank retreat, there is a need to identify the erosion mechanisms involved during a rainstorm, especially those associated with raindrops. The mechanisms include detachment and transport of particles as a result of splash and the fall down of entire soil aggregates.

This study was performed within the steep slopes of the KwaZulu-Natal province of South Africa, a region highly affected by gully erosion (Martin, 1987; Beckedahl, 1996). Linear erosion rates in this region are significantly higher than the natural soil pedogenesis (Martin, 1987) and thus represent a major threat to the non-renewable soil resource and its numerous associated ecological services linked to food production, water storage, and biodiversity. Deep incisions, locally named 'dongas', are shown to be mainly associated with the presence of certain parent materials (Weaver and van, 1991), such as unconsolidated colluvions which erode easily (Wintle et al., 1995), and are generally associated with high sodium contents (Yaalon, 1987). Moreover, from the literature it appears that in this region, gully bank retreat is more prominent compared to the retreat of gully head cuts (Martin, 1987), thus placing greater emphasis on the retreat of gully banks.

Nowadays, linear erosion may accelerate due to land use changes and/or misuses (Lal, 1998), as has occurred in this region, and result in decreased soil infiltration and increased runoff (Le Roux et al., 2007; Dlamini et al., this issue). Despite numerous studies on linear erosion, gully or donga systems, there is still a need for remediation techniques and a better understanding of the mechanisms and processes of their formation and evolution. In a recent study, Rienks et al. (2000) revealed (using an erodibility test) that the silt and sodium contents of the parent material have a great effect on soil erodibility, suggesting that dispersion plays an important role in linear erosion. Furthermore, little is known about the other mechanisms of gully evolution such as detachment and transport of soil particles due to raindrop impact and fall down of entire soil aggregates as a result of rainstorm events.

In this study, our main objective was to quantify the contribution of splash detachment, sediment transport by runoff and fall down of entire soil aggregates to overall erosion by rainfall from a gully bank. Erosion mechanisms are difficult to investigate and control during natural rainfall events, therefore rainfall simulation was used to reach the desired objectives. Rainfall was simulated for $45 \mathrm{~min}$, at a typical gully bank, and the erosion rate of the three mechanisms described was evaluated.

The study was conducted at the South African site of the Smallholder System Innovations (SSI) project which focuses on improved management of soil and water resources for small holder farmers livelihoods whose are strongly affected by the degradation of the soil resource.

\section{Materials and methods}

\subsection{The characteristics of the study site}

The study area is located in KwaZulu-Natal, South Africa (Fig. 1) in a $10 \mathrm{~km}^{2}$ watershed situated in the northern sloping lands of the Thukela basin $\left(30000 \mathrm{~km}^{2}\right)$. The site $\left(22^{\circ} 19^{\prime} 15^{\prime \prime} 3 \mathrm{~S} ; 22^{\circ} 49^{\prime} 52^{\prime \prime} 8 \mathrm{E}\right)$ is situated in a sub-tropical, semi-humid climate with summer rain- 


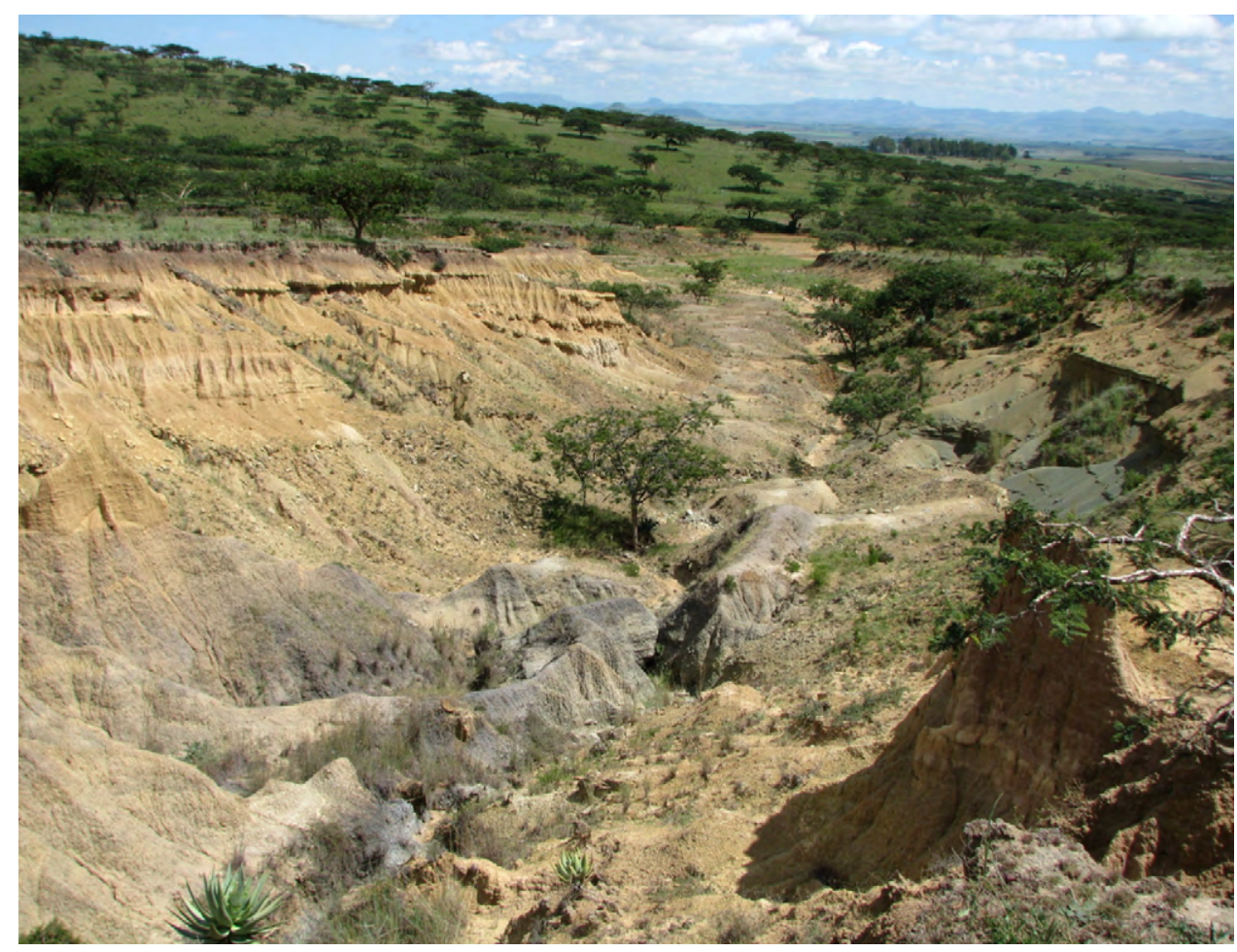

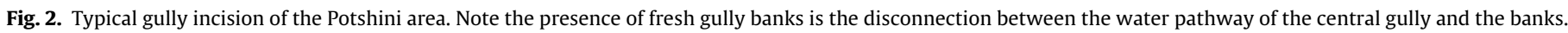

fall (October-March). At Bergville, located $10 \mathrm{~km}$ to the east, the mean annual precipitation over the last 30 years has been $684 \mathrm{~mm}$, with a potential evaporation of $1600 \mathrm{~mm}$ and a mean annual temperature of $13^{\circ} \mathrm{C}$ (Schulze, 1997). Altitudes range between 1080 and $1455 \mathrm{~m}$. The relief is relatively smooth with a mean slope gradient of about $15 \%$. Steep slopes on the upper watershed may however reach gradients of 50-70\%, while flat areas may be observed downstream. Cattle constitute the second most important part of the Zulu smallholders' livelihood, and because it is also an important cultural asset, the number of cattle has increased. This, combined with highly acidic soils of low productivity (Table 1), leads to rapid overgrazing with dramatic consequences on soil degradation (Fey, 2003; Dlamini et al., this issue) and especially gully erosion (Botha et al., 1994). At the study site the density of gully banks is approximately $500 \mathrm{~m}^{2} \mathrm{ha}^{-1}$ (Dlamini et al., this issue) (Fig. 2).

The gully of interest for this study is situated on the northern upper limit of the catchment. The selected bank was $30 \mathrm{~m}$ downslope of the gully head cut. A representative $1 \mathrm{~m}$ wide zone was selected in an area accessible from the road and with a flat bottom in order to facilitate the experiment. The gully bank that was $10 \mathrm{~m}$ away from the gully center is a typical Luvisol (WRB, 1998) characterized by a thick Fragic horizon. The surface $0-0.1 \mathrm{~m}$ horizon is brown (10YR 4/3), very coherent and has a medium, subangular, blocky structure. It is a sandy silt horizon with many roots. The horizon directly below $(0.1-0.2 \mathrm{~m})$ is an organo-mineral, sandy silt, that is coherent, yellowish brown horizon (10YR 5/4) with a clear medium, subangular, blocky structure. A mineral Fragic horizon, $1 \mathrm{~m}$ thick, lies below this. It is a yellowish brown (5YR 5/4), sandy clay, that is slightly coherent and exhibits a massive to columnar structure. The transition to the underlying horizon is sharp. It is a light grey, sandy silt with a massive structure.

\subsection{The evaluation of the different mechanisms of erosion induced by rainfall}

Rainfall was simulated on 20 November 2008 to evaluate the potential gully bank retreat resulting from rainfall erosion. This date followed a dry period of about six months and the soil horizons were all dry.

The gully bank was covered with plastic sheeting, except for a $1 \mathrm{~m}$ wide portion which remained exposed. Rainfall intensity was applied to the exposed portion at a rate of $60 \mathrm{~mm} \mathrm{~h}^{-1}$ for $45 \mathrm{~min}$, simulating a typical rainfall event of the region (Schulze, 1997). The rainfall was produced using an ORSTOM simulator (Valentin, 1978). The simulator comprised an oscillating nozzle (Teejet SS 6560) which was aligned with the center of the exposed portion of the vertical bank, approximately $4 \mathrm{~m}$ above the soil surface. A valve and a pressure gauge were located at the same altitude as the nozzle, allowing for precise control of water pressure and consequently the maintenance of a consistent rain kinetic energy. At a water pressure of $40 \mathrm{kPa}$ the estimated kinetic energy was $25 \mathrm{~J} \mathrm{~m}^{-2} \mathrm{~mm}^{-1}$.

The rainfall intensity was set and controlled electronically prior to the experiment. Error for rainfall intensity was assumed to be less than $5 \%$.

The vertical runoff, along with its sediments was evaluated using a $1 \mathrm{~m}^{2}$ microplot inserted within the base of the bank (Fig. 3) during the rainfall period. The sampling protocol involved sampling the initial runoff in three consecutive $500 \mathrm{ml}$ bottles. The proceeding $500 \mathrm{ml}$ aliquots were collected every $5 \mathrm{~min}$ to the 20th minute and every $5 \mathrm{~min}$ to the end of the experiment. These bottles were then labelled and the time taken to fill them recorded. The splash material was collected using twelve rectangular $0.27 \mathrm{~m} \times 0.17 \mathrm{~m}$ $\left(0.045 \mathrm{~m}^{2}\right)$ buckets, positioned at the node of a regular grid of $0.5 \mathrm{~m}$ increments. The minimum distance from the source (i.e., the gully bank) was $0.5 \mathrm{~m}$ and the maximum was $1.5 \mathrm{~m}$. Finally, fallen soil aggregates were gathered from the $1 \mathrm{~m}^{2}$ microplot after the simulation had stopped.

The $500 \mathrm{ml}$ aliquots of runoff water were dried at $105^{\circ} \mathrm{C}$ to evaluate the sediment concentration in the runoff. The runoff fluxes were estimated over time by using the filling duration of bottles. Total sediment lost during a bottle filling period corresponded to the product of the sediment concentration in that bottle and its runoff volume. Data were then integrated over the duration of the rainfall to calculate the total soil loss as a result of runoff. Sediments 

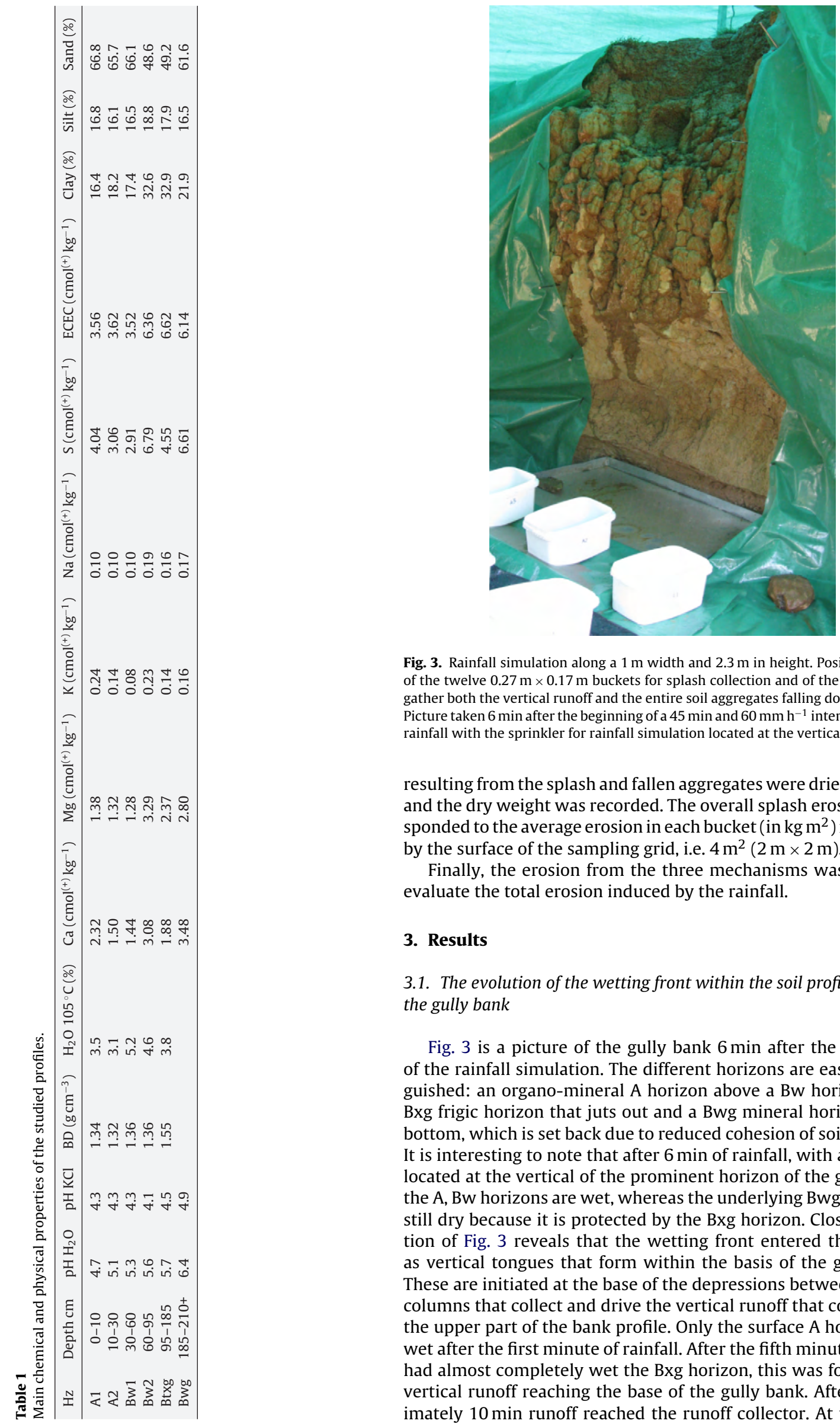

Fig. 3. Rainfall simulation along a $1 \mathrm{~m}$ width and $2.3 \mathrm{~m}$ in height. Position of some of the twelve $0.27 \mathrm{~m} \times 0.17 \mathrm{~m}$ buckets for splash collection and of the microplot to gather both the vertical runoff and the entire soil aggregates falling down the bank. Picture taken $6 \mathrm{~min}$ after the beginning of a $45 \mathrm{~min}$ and $60 \mathrm{~mm} \mathrm{~h}^{-1}$ intensity artificial rainfall with the sprinkler for rainfall simulation located at the vertical of the bank.

resulting from the splash and fallen aggregates were dried at $105^{\circ} \mathrm{C}$ and the dry weight was recorded. The overall splash erosion corresponded to the average erosion in each bucket (in $\mathrm{kg} \mathrm{m}^{2}$ ) multiplied by the surface of the sampling grid, i.e. $4 \mathrm{~m}^{2}(2 \mathrm{~m} \times 2 \mathrm{~m})$.

Finally, the erosion from the three mechanisms was added to evaluate the total erosion induced by the rainfall.

\section{Results}

\subsection{The evolution of the wetting front within the soil profile of the gully bank}

Fig. 3 is a picture of the gully bank 6 min after the beginning of the rainfall simulation. The different horizons are easily distinguished: an organo-mineral A horizon above a Bw horizon and a Bxg frigic horizon that juts out and a Bwg mineral horizon at the bottom, which is set back due to reduced cohesion of soil particles. It is interesting to note that after 6 min of rainfall, with a sprinkler located at the vertical of the prominent horizon of the gully bank, the A, Bw horizons are wet, whereas the underlying Bwg horizon is still dry because it is protected by the Bxg horizon. Closer inspection of Fig. 3 reveals that the wetting front entered the horizon as vertical tongues that form within the basis of the gully bank. These are initiated at the base of the depressions between the Bxg columns that collect and drive the vertical runoff that comes from the upper part of the bank profile. Only the surface A horizon was wet after the first minute of rainfall. After the fifth minute, the rain had almost completely wet the Bxg horizon, this was followed by vertical runoff reaching the base of the gully bank. After approximately 10 min runoff reached the runoff collector. At the end of 

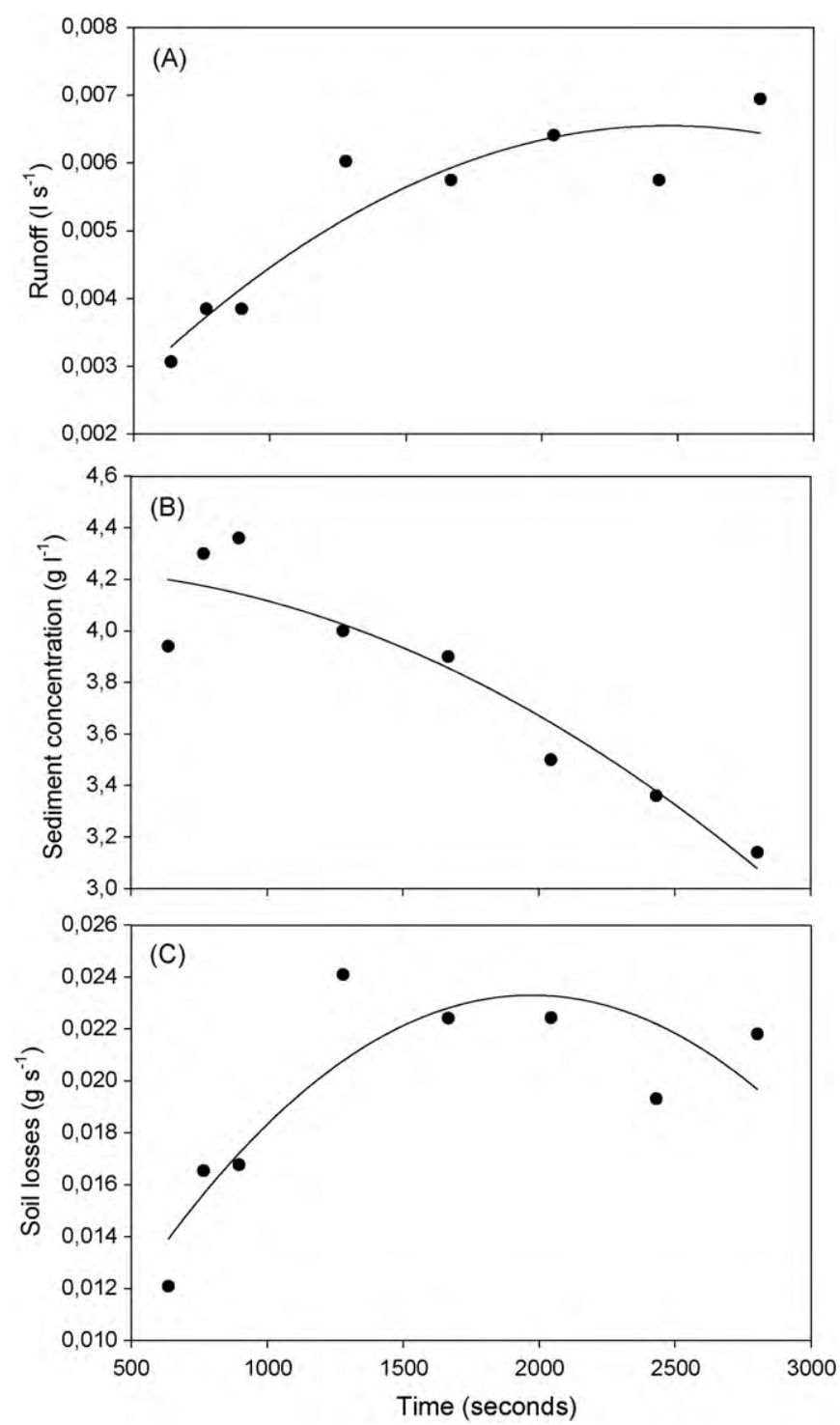

Fig. 4. Evolution over time of runoff, sediment concentration and sediment losses from the vertical runoff and during the $45 \mathrm{~min}$ and $60 \mathrm{~mm} \mathrm{~h}^{-1}$ artificial rainfall. Ajustement of data point by using quadratic functions.

the rainfall event, three main runoff pathways had crossed on the underlying horizon, and the rest of the surface remained dry.

\subsection{Vertical runoff (R) and its sediment concentration (SC)}

The cumulative runoff collected at the base of the gully bank was $14.05 \mathrm{l}$. The runoff fluxes varied between $3 \times 10^{-3}$ and $7 \times 10^{-3} 1 \mathrm{~s}^{-1}$. Runoff rate showed a sharp increase from the initiation of runoff to the 20th minute of rainfall, after which runoff rate increased more gradually (Fig. 4A). The average sediment concentration in the runoff was $3.8 \mathrm{~g} \mathrm{l}^{-1}$ and values varied between 3.1 and $4.4 \mathrm{~g} \mathrm{l}^{-1}$ (Fig. 4B). Despite a sharp increase during the first minutes of runoff, sediment concentration significantly decreased over time.

As expected from the evolution of $R$ and SC over time, the computed soil losses showed a sharp increase from $0.012 \mathrm{~g} \mathrm{~s}^{-1}$ to about $0.024 \mathrm{~g} \mathrm{~s}^{-1}$ at $25 \mathrm{~min}$ of rainfall and a slight decrease to the end of the rainfall event (Fig. 4C). As a result, the computed soil lost during the artificial rainfall of $45 \mathrm{~min}$ was $723 \mathrm{~g}$, which corresponded to an erosion rate of $450 \mathrm{~g} \mathrm{~m}^{-2} \mathrm{~h}^{-1}$ (Fig. 5). This erosion rate seems relatively low but when extrapolated to about $500 \mathrm{~m}^{2}$ of bank observed

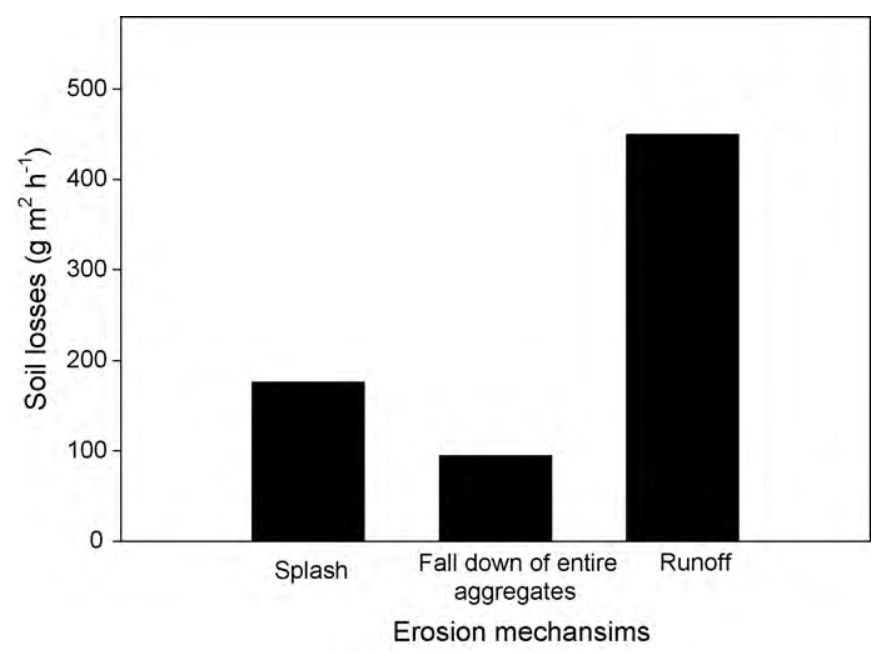

Fig. 5. Cumulative soil erosion for the different erosion mechanisms.

per hectare, it would correspond to an erosion rate of $4.5 \mathrm{th}^{-1}$ which already represents high amounts.

\subsection{Splash erosion and fall down of entire soil aggregates}

As shown in Fig. 3, splash erosion seemed to only occur on the $\mathrm{A}$ and $\mathrm{Bw}$ and the top of Bxg horizons, the only horizons wet by raindrops. The average value of sediment erosion caused by splash, calculated from the 10 buckets, was $76 \mathrm{~g} \mathrm{~m}^{-2}$. The CV of splash deposition rate was very high (160\%), reflecting values between 4.1 and $419 \mathrm{~g} \mathrm{~m}^{-2}$ (corresponding to 5.5 and $557 \mathrm{~g} \mathrm{~m}^{-2} \mathrm{~h}^{-1}$, respectively). The rate of deposition of soil particles did not occur randomly, but as expected decreased sharply with distance from the gully bank. The average deposition rate was $258 \mathrm{~g} \mathrm{~m}^{-2} \mathrm{~h}^{-1}$ at $0.5 \mathrm{~m}$ from the bank, which decreased to $37 \mathrm{~g} \mathrm{~m}^{-2} \mathrm{~h}^{-1}$ at $1 \mathrm{~m}$ and to $8.3 \mathrm{~g} \mathrm{~m}^{-2} \mathrm{~h}^{-1}$ at $1.5 \mathrm{~m}$. As a result, the computed sedimentation, due to splash, on the $4 \mathrm{~m}^{2}$ area where splash deposition was shown to occur, was $405 \mathrm{~g} \mathrm{~h}^{-1}$ corresponding to $176 \mathrm{~g} \mathrm{~m}^{-2} \mathrm{~h}^{-1}$ per $\mathrm{m}^{2}$ of gully bank. Finally, a $164 \mathrm{~g}$ aggregate detached from the gully bank during the course of the experiment and resulted in an overall erosion rate of $94 \mathrm{~g} \mathrm{~m}^{-2} \mathrm{~h}^{-1}$ (Fig. 5).

Overall, the erosion rate computed from runoff, splash and erosion due to fall down of entire soil aggregates was $721 \mathrm{~g} \mathrm{~m}^{-2} \mathrm{~h}^{-1}$.

\section{Discussion}

\subsection{Overall erosion of gully banks}

The overall erosion rate calculated from runoff, splash and erosion due to fall down of entire soil aggregates was $721 \mathrm{~g} \mathrm{~m}^{-2} \mathrm{~h}^{-1}$. Extrapolated to the annual rainfall of $800 \mathrm{~mm}$ (Schulze, 1997), with the assumption of similar impact to the simulated rainfall, the total erosion might reach $9.6 \mathrm{~kg} \mathrm{~m}^{-2} \mathrm{y}^{-1}$. Such an amount corresponds to an annual average bank retreat of about $7 \mathrm{~mm}$ for an average soil bulk density of $1.35 \mathrm{~g} \mathrm{~cm}^{-3}$.

Given that about $500 \mathrm{~m}^{2}$ of bank is present per ha at the watershed level, extrapolation or soil losses would lead to $4.8 \mathrm{tha}^{-1}$. This rate of gully bank retreat is slightly higher than that observed in Kenya (3 tha $y^{-1}$, Oostwoud Wijdenes and Bryan, 2001), and in catchments under sloping land conditions in Northern Laos, as described by Chaplot et al. (2005), which have rates of between 0.1 and 2.4 tha $^{-1}$. Gully erosion at our site was significantly lower than rates measured under temperate or Mediterranean conditions (Govers and Poesen, 1988) for Belgium at $22 \mathrm{tha}^{-1}$, and Casali et al. (2003) and Poesen et al., 2002 (between 38 and 65 tha $^{-1}$ ). 
Lower erosion rates in northern Laos may be explained by a high structural stability provided by high clay and organic matter contents (Chaplot et al., 2007) while in our study the cohesion of the Bxg horizon buffer the local erosion rate compare to the values measured under temperate and Mediterrainean conditions.

Soil erosion due to gully bank retreat should be considered with respect to the other forms of erosion within the area. Since the area is under pasture with no artificial perturbation, erosion by tillage is assumed to be near zero. Estimations of interrill erosion (Kinnell, 2001 ) at the same site revealed great amounts of soil are removed due to splash and shallow runoff. Dlamini et al. (this issue) calculated the average interrill erosion rate to be $7.7 \mathrm{tha}^{-1}$, by using fifteen $1 \mathrm{~m}^{2}$ microplots installed within the catchment, in between gullies.

\subsection{The different mechanisms of gully bank retreat during the} rain

From our investigations, runoff ( $62 \%$ of total soil loss) contributed the most to the overall erosion rate followed by splash erosion (24\%) and fall down of aggregates (13\%).

Sediment transport due to runoff sharply increased during the first minutes of the artificial rainfall and significantly decreased afterwards. The first increase in sediment concentration (SC) may be explained by the fact that on very dry soil (less than $5 \%$ of moisture) with exposed flank to soil evaporation, sediment detachment and transport need a certain time to be effective. From the soil detachment point of view, the different disaggregation mechanisms (slaking, mechanical breakdown and chemical dissolution) require the wetting front to penetrate the soil aggregates deeply (Le Bissonnais, 1996). Runoff must reach a certain velocity to transport this material (Chaplot and Le Bissonnais, 2003). The decrease of SC over time might be explained by a dilution effect, i.e. the sediment detachment is diluted in a greater runoff volume, and/or by the fact that disaggregation mechanisms are very effective on a dry soil and when the easily detachable material is exported the remaining aggregates are less erodible.

Overall, greater erosion by runoff than by splash may be explained by the fact that sediment detached by splash is more easily transported by runoff than by splash itself (Kinnell, 2001). It is important to note that at the first stage of the simulation, when the soil surface at the bank was still dry, splash erosion and transport was the only operative mechanisms of gully bank retreat.

Such results show that other than dispersion (which has been proven to play an important role in linear erosion), mechanical disaggregation is another important mechanism that favors gully erosion and occurs under conditions where sodium content is high (Rienks et al., 2000). Such results seem to show the great impact that splash that plays on disaggregation by slaking, mechanical breakdown or chemical dispersion.

It is surprising that fall down of entire soil aggregates was listed third on the list of erosion mechanisms, especially considering the large amount of aggregates generally found in the vicinities of banks that have fallen down as individuals or as massive "landslides" of several $\mathrm{m}^{3}$. The question thus arises: how is it possible that the fall down of aggregates only contributes to $13 \%$ of our total soil losses? One possible explanation is probably due to the time frame used for the study. Where splash is active at the rainfall event only, fall down of blocks may occur either during or between rainfall events, due to swelling and shrinking as a result of wetting and drying of the soil. For this reason this process is likely to have been underestimated. Longer periods of observation as well as longer portions of gully banks would need to be considered to assess the hazardous behavior of aggregate fall down and the exact timing of the collapse of entire portions of gully bank, that produce very large amounts of sediments which may be eroded and be transported by splash and runoff. The second possible explanation is that the soil type is highly impacting the bank retreat process. Soils derived from sandstone and colluviums show a low aggregation. On dolerite, surface morphologic features appear completely different with a very clear stable fine structure very prone to detachment. Further comparative research studies are therefore necessary.

\section{Conclusion}

In this study our main objective was to identify the storm-scale mechanisms of gully bank retreat and this was investigated by collecting soil erosion resulting from runoff, splash transport and fall down of soil aggregates, during an artificial rainfall event.

Two main conclusions could be drawn from this study:

1. The retreat of gully banks is confirmed to be a main process in overall gully evolution and overall erosion in landscapes.

2. Soil erosion due to raindrops and runoff is very active mechanism of gully bank retreat. Runoff contributed to about $90 \%$ of total exports. Fall down of entire aggregates proved to be the least significant on that type of soil.

Considering splash is an important factor of bank retreat at the rainfall event level, remediation of gully evolution might be obtained through an improved protection of the surface of gully banks from raindrops by increasing for instance soil surface coverage by vegetation (e.g., Morgan, 2004).

However, further research studies, that investigate the erosion mechanisms for longer periods and on larger areas, need to be performed to gather more data for a single storm event, and to emphasize the hazardous behavior of the fall down of soil aggregates or landsliding of gully banks.

\section{Acknowledgments}

This study was organized and managed during a summer-school session of IRD-school of Bioresources Engineering and Environmental Hydroloby of the University of Kwasulu-Natal. Staff and students together conceived and realized the rainfall simulation, and collected and analyzed the data in this jointly prepared paper. The authors gratefully acknowledge the Département Soutien Formation (DSF) of the Institut de Recherche pour le Développement (IRD, former ORSTOM) and the School of Bioresources Engineering and Environmental Hydrology, Rabie Saunders Building, University of Kwazulu-Natal, its Director, Jeff Smithers, for funding this research in the framework of their capacity building program, and providing support and assistance. We also thank the University of Pretoria, the Sugarcane Research Institute (SASRI) of South Africa and the BIOEMCO of Grignon (France) for collaboration. This study was as well performed under the umbrella of the Small-holder System Innovations (SSI) project which focuses on improved management of soil and water resources for small holder farmers. The SSI Programme was funded by the Netherlands Foundation for the Advancement of Tropical Research (WOTRO), the Swedish International Development Cooperation Agency (Sida), the Netherlands Directorate-General of Development Cooperation (DGIS), the International Water Management Institute (IWMI) and UNESCOIHE Institute for Water Education. Special thanks must also go to the Potshini community for kindly allowing the research to be performed on their land, and for their technical assistance, and to Lucas Janeau for helping in drying samples. Final thanks go to the two anonymous reviewers and to the guest Editor of this special issue, Dr. Deborah Bossio, for having improved the manuscript. 


\section{References}

Beckedahl, H.R., 1996. Subsurface soil erosion phenomena in Transkei and southern KwaZulu-Natal, South Africa. PhD Thesis, University of Natal, Pietermaritzburg, South Africa, p. 224.

Botha, G.A., Wintle, A.G., Vogel, J.C., 1994. Episodic late Quaternary palaeogully erosion in northern KwaZulu-Natal, South Africa. Catena 23, 327-340.

Casali, J., Lopez, J.J., Giraldez, J.V., 2003. A process-based model for channel degradation: application to ephemeral gully erosion. Catena 50, 435-447.

Chaplot, V., Le Bissonnais, Y., 2003. Runoff features for interrill erosion at different rainfall intensities, slope lengths and gradients in an agricultural loessial hillslope. Soil Science Society of America Journal 67, 844-851.

Chaplot, V., Coadou le Brozec, E., Silvera, N., Valentin, C., 2005. Spatial and temporal assessment of linear erosion in catchments under sloping lands of Northern Laos. Catena 63, 167-184.

Chaplot, V., Khampaseuth, X., Valentin, C., Le Bisonnais, Y., 2007. Interrill erosion in the sloping lands of northern Laos submitted to shifting cultivation. Earth Surface Processes and Landforms 32, 415-428.

DiCenzo, P.D., Luk, S.H., 1997. Gully erosion and sediment transport in a small subtropical catchment, South China. Catena 29, 161-176.

Dlamini, P., Podwojewski, P., Janeau, J.-L., Lorentz, S., Jewitt, G., Chaplot, V., this issue. Controlling factors of Interrill erosion of sloping-land-agricultural-soils in KwaZulu Natal (South Africa). Agricultural Water Management (the same issue).

Govers, G., Poesen, J., 1988. Assessment of the interrill and rill contributions to total soil loss from an upland field plot. Geomorphology 1, 343-354.

Hu, G., Wu, Y., Liu, B., Yu, Z., You, Z., Zhang, Y., 2007. Short-term gully retreat rates over rolling hill areas in black soil of Northeast China. Catena 2, 321-329.

IGBP (International Geosphere-Biosphere Programme), 1995. Land-use and land cover change. Science Research Plan, Stockholm, 123.

Kinnell, P., 2001. Comments on "vertical hydraulic gradient and run-on water and sediment effects on erosion processes and sediment regimes". Soil Science Society of America Journal 65, 953-957.

Lal, R., 1998. Soil erosion impact on agronomic productivity and environment quality. Critical Review in Plant Science 17, 319-464.

Le Bissonnais, Y., 1996. Aggregate stability and assessment of soil crustability and erodibility. I. Theory and methodology. European Journal of Soil Science 47, 425-437.

Le Roux, J.J., Newby, T.S., Summer, P.D., 2007. Monitoring soil erosion in South Africa at a regional scale: review and recommendations. South African Journal of Science 103, 329-335.

Martin, A.K., 1987. Comparison of sedimentation rates in the Natal Valley, southwest Indian Ocean, with modern sediment yields in east coast rivers of Southern Africa. South African Journal of Science 83, 716-724.
Montgomery, D.R., Dietrich, W.E., 1994. Landscape dissection and drainage areaslope thresholds. In: Kirkby, M.J. (Ed.), Process Models and Theoretical Geomorphology. Wiley, Chichester, pp. 221-245.

Moore, J.S., Temple, D.M., Kirsten, H.A.D., 1994. Headcut advance threshold in earth spillways. Bulletin of the International Association of Engineering Geology 31, 277-280.

Morgan, R.P.C., 2004. Soil Erosion and Conservation. Wiley-Blackwell, ISBN 978-14051-1781-4, p. 320.

Nachtergaele, J., Poesen, J., Steegen, A., Takken, I., Beuselinck, L., Vandekerckhove L., Govers, G., 2001. The value of a physically based model versus an empirical approach in the prediction of ephemeral gully erosion for loess-derived soils. SO Geomorphology 40, 237-252.

Oostwoud Wijdenes, D.J., Bryan, R.B., 2001. Gully-head erosion processes on a semiarid valley floor in Kenya: a case study into temporal variation and sediment budgeting. Earth Surface Processes and Landforms 26, 911-933.

Poesen, J., Vandaele, K., van Wesemael, B., 1996. Contribution of Gully Erosion to Sediment Production in Cultivated Lands and Rangelands, vol. 236. IAHS Publications, pp. 251-266.

Poesen, J., Vandekerckhove, L., Nachtergaele, J., Oostwoud Wijdenes, D., Verstraeten, G., van Wesemael, B., 2002. Gully erosion in dryland environments. In: Bull, L.J., Kirkby, M.J. (Eds.), Dryland Rivers: Hydrology and Geomorphology of Semi-Arid Channels. Wiley, Chichester, UK, pp. 229-262.

Rienks, S.M., Botha, G.A., Hughes, J.C., 2000. Some physical and chemical properties of sediments exposed in a gully-donga/in northern KwaZulu-Natal, South Africa and their relationship to the erodibility of the colluvial layers. Catena 39, 11-31.

Schulze, R.E., 1997. South African Atlas of Agrohydrology and Climatology. TT82/96 Water Research Commission, Pretoria, RSA.

Valentin, C., 1978. Problèmes méthodologiques liés à la simulation de pluies. Application à l'étude de l'érodibilité des sols. In: Vogt, H. $</ E d>$ (Ed.), Colloque 'érosion agricole'. Université de Strasbourg, pp. 117-122.

Vandekerckhove, L., Poesen, J., Oostwoud Wijdenes, D., Gyssels, G., 2001. Shortterm bank gully retreat rates in Mediterranean environments. Catena 44, 133161.

Weaver, A., van, B., 1991. The distribution of soil erosion as a function of slope aspect and parent material in Ciskei, South Africa. GeoJournal 23, 29-34.

Wintle, A.G., Botha, G.A., Li, S.H., Vogel, J.C., 1995. A chronological framework for Watson, H. K., 1996. Short and long-term influence on soil erosion of settlement by peasant farmers in KwaZulu-Natal. South African Geographical Journal 78, $1-6$.

Yaalon, D.H., 1987. Is gullying associated with highly sodic colluvium? Further comment to the environmental interpretation of southern african dongas. Palaeogeography, Palaeoclimatology, Palaeoecology 58, 121-123. 